\title{
土木工程建筑中混凝土结构的施工技术分析
}

叶宏平屠方明

浙江富恒建设工程有限公司，浙江嵊州 312400

[摘要]在社会快速发展的带动下，使得民众的生活质量得到明显的进步，进而也促进了人们的思想意识的提升，这样导致人 们对建筑工程各方面质量和性能的要求在逐渐的提升。就一个土木工程建造工序来说，最为关键的工作就是保证混凝土结构 的施工质量, 混凝土结构的施工技术的水平与土木工程整体质量存在密切的关联, 只有促进混凝土结构施工技术的稳步提升 才能从根本上保证建筑整体的结构稳定性。这篇文章主要围绕土木工程建造中混凝土结构中的施工技术展开全面的分析, 希 望对这项技术的发展进步有所助益。

[关键词]土木工程建筑; 混凝土结构; 施工技术

DOI: $10.33142 /$ sca.v2i3.624

中图分类号：TU755 文献标识码：A

\section{The Analysis of the Construction Technology of the Concrete Structure in Civil Engineering}

\author{
YE Hongping, TU Fangming
}

Zhejiang Fuheng Construction Engineering Co., Ltd., Zhejiang Shengzhou, 312400

\begin{abstract}
Driven by the rapid development of society, the quality of life of the people has been obviously improved, and then the improvement of people's ideology has been promoted, which leads to the gradual improvement of the quality and performance of construction engineering. As far as a civil engineering construction process is concerned, the most critical work is to ensure the construction quality of concrete structure. The level of concrete structure construction technology is closely related to the overall quality of civil engineering. Only by promoting the steady improvement of concrete structure construction technology can the overall structural stability of the building be fundamentally guaranteed. This article focuses on coagulation in civil engineering construction. The construction technology in soil structure is analyzed comprehensively, which is hoped to be helpful to the development and progress of this technology.
\end{abstract}

Keywords: Civil engineering construction; Concrete structure; Construction technology

\section{引言}

随着我国经济的飞速发展，我国在城市建设方面也取得了的令人瞩目的成绩，但是在土木工程的施工工作中也发 现了一些需要关注的质量问题。这些质量问题中比较突出的就是混凝土结构上的质量问题, 比如混凝土结构的开裂, 混凝土的开裂严重影响了整体建筑结构的完整性, 不仅降低了土木工程的施工质量, 还会在使用时出现渗水问题, 水 体通过裂缝接触到混凝土结构内部的钢筋, 还会腐蚀钢筋, 最终降低建筑结构的使用寿命。因此, 为了保证混凝土结 构施工质量，需要提高施工技术水平，改善施工中的不足，最终保证土木工程的整体施工质量。

\section{1 土木工程建筑中混凝土结构内容阐述}

混凝土结构在土木工程整体结构中的作用是非常重要的, 并且现如今混凝土结构已经被人们大范围的运用 到了各种类型的工程建造之中。混凝土结构其最为主要的施工物料为混凝土, 其实质就是将砂石和水按照前期 计算的比例依据一定的顺序进行添加之后混合形成的一种物料, 混凝土物料具有良好的强度, 具有良好的适用 性。混凝土结构受到人们的喜爱的主要原因主要为下面几个方面: 首先, 混凝土的所有的原材料的花费较少, 并且制作工序十分的简单。其次, 混凝土结构具备良好的抵抗外界作用力的性能, 能够达到各种类型的工程的 实际需求的条件。再有, 混凝土的燃点极高, 具有良好的稳定性, 在混凝土结构建造完成之后, 结构的质量保 证较好。还有, 混凝土施工中具有良好的灵活性, 能够建造出需要的各种形状。最后, 混凝土因为具备良好的 可塑性, 进而在其完全凝结后出现塑性裂缝的概率也是非常高的, 这样就损害了整个建筑结构的质量, 缩减了 建筑结构的使用时长, 想要有效的解决上述问题, 需要施工人员结合实际情况制定有效的解决方案, 规避混凝 土结构出现裂缝的问题 [1]。 


\section{2 混凝土结构施工过程中存在的问题分析}

\section{1 温度因素}

在土木工程混凝土结构建造完成之后, 一旦环境温度波动较大, 就会导致混凝土结构内外结构出现严重的温差, 进而会导致结构裂缝情况的发生。

\section{2 水泥热化反应因素}

如果在工程项目建造中, 水泥物料的选用与实际需要不一致的时候, 极易引发施工中水泥热化反应出现, 在整个 反应中会释放出大量的热能, 这就会影响到混凝土内部的温度在短时间内明显的提升, 进而会导致内外结构的温差情 况, 最终发生结构裂缝 [2]。

\section{3 混凝土自缩现象}

在混凝土结构建造完成之后, 混凝土结构会慢慢的凝结, 在整个过程中, 整个结构都会维持在一个恒温的状态, 并且混凝土的水分与外界也是不能来进行交换的, 在这个形势下, 混凝土结构整体结构的规格会逐渐的变小, 这样就 会导致结构裂缝问题的出现。

\section{3 提高混凝土结构质量的改进技术}

\section{1 加强施工材料的质量监督}

在施工初期, 施工质量监管部门应该做好对施工材料的审核工作, 施工材料的采买阶段, 管理人员与采购人员应 该密切配合, 保证施工材料质量符合设计标准。采购人员在进行施工材料的选择时, 要严格核对商家提供的产品质量 认证文件, 管理人员应该监督采购人员的具体工作, 避免出现采购人员利用职务便利窃取企业资源最终影响施工质量 的问题。在施工中管理人员也应该加强对施工材料的抽查工作, 保证施工环节不会出现以次充好的问题, 保证施工材 料的质量, 可以有效的加强土木工程的最终质量, 减少混凝土结构开裂问题的发生 [3]。

\section{2 做好施工质量管理工作}

在混凝土结构的浇筑环节, 也需要严格控制施工流程的规范性, 只有保证混凝土搅拌工作质量, 才能让混凝土材 料混合均匀, 再通过一次性浇筑的手段加强混凝土结构的整体性。在混凝土结构的养护阶段, 需要做好混凝土结构表 面的保湿和保暖工作。在混凝土的养护时期, 如果因为温度的剧烈变化会使混凝土出现热胀冷缩的现象, 进而因为混 凝土互相挤压而产生裂缝。混凝土的凝结需要一个缓慢的阴干过程, 不能做好保湿工作就会让混凝土表面湿度瞬间降 低, 混凝土结构内部和外表湿度差距过大就会影响整体强度, 最终因为干燥产生裂纹。也可以通过其他先进施工技术 的引入来降低施工难度, 例如后浇带施工技术, 通过预留后浇带来降低主体结构之间相互的影响, 在整体结构成型后 对后浇带区域进行填充, 最终实现整体结构的完整性。

\section{3 根据情况加强混凝土强度标准}

在施工设计阶段, 应该根据实际情况提高混凝土的强度标准, 通过加入添加剂的方法, 提高混凝土的强度, 同时 提高混凝土的抗拉伸能力。在设计时应该做好对施工地点土质结构信息的详细采集, 对于一些土质结构比较薄弱的区 域应该加强地基的加固, 通过加厚地基或改变结构的方式加强地基的承载能力, 进而保证混凝土结构不会因为土质沉 降而变形。也可以通过不同施工技术的应用来降低施工中沉降因素对混凝土结构的印象, 通过预留沉降区域来降低地 基对混凝土结构的约束 $[4]$ 。

\section{4 土木工程项目中混凝土结构施工技术}

\section{1 混凝土的摚拌与运输}

在一般时候, 混凝土结构的建造中, 在实施混凝土制作工序的时候, 都会运用到混凝土搅拌以及运送。在实施混 凝土搅拌工序的时候, 工作人员务必要对下面几项工作加以侧重关注。首先务必要结合现实情况以及规范标准来对混 凝土实施摚拌。其次, 在摚拌的时候, 可以利用间歇摚拌的形式, 并且需要对混凝土中冷热物料的添加量加以控制, 并对环境温度进行一定的管控。最后, 在实施混凝土摚拌之前需要对添加的所有的成分的添加量进行计算保证混凝土 的质量。 


\section{2 混凝土的接缝和切缝技术}

在整个土木工程的建造中，混凝土各个部分结构衔接位置的质量是非常关键的，与整个结构的稳定性存在一定的 关联, 进而需要我们在实际施工的时候加以侧重关注, 在针对混凝土结构衔接位置进行建造的时候利用接缝或者是切 缝技术来保证整个机构的质量。首先，需要遵照施工实际情况来对施工技术来进行挑选，保证各项工作都能够达到既 定的标准。其次, 在通常时候需要借助切割工具来讲混凝土中多余的部分进行切除, 之后利用混凝土物料来针对接缝 实施处理。最后, 在利用接缝技术的过程中, 最为重要的是对施工现场温度的管控, 务必要确保在既定的范围之内, 温度与接缝操作的结果是存在密切的关联的 [5]。

\section{3 混凝土浇筑}

在实施混凝土物料浇筑施工的时候, 需要结合现实需求对每一层混凝土的厚度加以控制, 并且需要保持逐层浇筑 的施工形式。首先务必要确保上层的混凝土会覆盖完整的下沉混凝土, 并且需要对两层混凝土施工时间间隔加以管控, 这样做的目的就是避免发生逐层凝结的情况。一般时候, 在下层没有完成初步凝结的时候就开始进行上层混泥土的浇 筑操作。

如果超出时间的话就会造成混凝土的出现裂缝, 并且在浇筑的过程中还要注意天气情况, 避免在大风、多雨多雪 的环境下进行混凝土浇筑, 大风寒冷的天气下会造成混凝土中水分的过早的流失, 在多雨多雪的时候会对混凝土水分 的含量产生不利的影响，这些都不利于混凝土施工的质量 [6]。

\section{结语}

土木工程建筑当中，其工程质量一直是我们非常看重的一个问题，在这当中最重要的就是要控制好混凝土的施工 质量。严格的控制好所选择的施工材料, 同时还要要求施工人员有着较高的技术, 所以这就要求相应的施工人员要全 面掌握混凝土相关施工技术，对混凝土的质量进行严格控制并且在实际施工中也要学会合理应用，只有这样认真的对 待并解决这些问题，才能进一步确保土木建筑工程的整体质量。

\section{[参考文献]}

[1]蒋秋生.对土木工程建筑中混凝土结构施工技术的研究 [J]. 建材与装饰, 2017 (07): 10-11.

[2]万雯逸. 土木工程建筑中混凝土结构的施工技术分析 [J]. 南方农机, 2017,48(16): 79.

[3] 段富振. 土木工程建筑中混凝土结构的施工技术分析 [J]. 河南科技, 2015(11) : 59-60.

[4] 孙中华. 土木工程建筑中混凝土结构的施工技术分析 [J]. 建材与装饰, 2018(12): 45.

[5]刘明灿. 土木工程建筑中混凝土结构的施工技术分析 [J]. 住宅与房地产, 2018 (13) : 241.

[6] 李进功. 土木工程建筑中混凝土结构的施工技术分析 [J]. 住宅与房地产, 2018(30): 174 .

作者简介: 叶宏平 (1962.10-), 工程师，专科。屠方明（1984.9-)，工程师，本科。 